\title{
HIGH-PRESSURE BURNING RATE STUDIES OF SOLID ROCKET PROPELLANTS
}

\author{
A. I. Atwood, K. P. Ford, and C. J. Wheeler \\ Naval Air Warfare Center Weapons Division \\ 1 Administration Circle, China Lake, California 93555, USA
}

\begin{abstract}
Increased rocket motor performance is a major driver in the development of solid rocket propellant formulations for chemical propulsion systems. The use of increased operating pressure is an option to improve performance potentially without the cost of reformulation. A technique has been developed to obtain burning rate data across a range of pressures from ambient to $345 \mathrm{MPa}$. The technique combines the use of a low loading density combustion bomb with a high loading density closed bomb technique. A series of nine ammonium perchlorate (AP) based propellants were used to demonstrate the use of the technique, and the results were compared to the neat AP burning rate "barrier." The effect of plasticizer, oxidizer particle size, catalyst, and binder type were investigated.
\end{abstract}

\section{INTRODUCTION}

Increasing performance remains a principal goal in the design of solid rocket motors. Traditional formulations and rocket motor designs have reached their optimum performance levels under current operating conditions. Formulations containing new ingredients are being investigated but this approach is costly and time consuming. Novel rocket motor grain designs and operating conditions are also being considered as options in the search for increased performance.

One means used to examine the performance of a proposed solid rocket propellant formulation is to examine the theoretical specific impulse of the formulations as the value scales to range velocity and payload. Improvements or, at least, maintenance of the propellant specific impulse are required in formulations. Performance requirements are of a particular concern in the area of reduced or minimum signature where the absence of metal in the formulation results in a substantial decrease in propellant specific impulse.

This is an Open Access article distributed under the terms of the Creative Commons Attribution License 2.0, which permits unrestricted use, distribution, and reproduction in any medium, provided the original work is properly cited. 


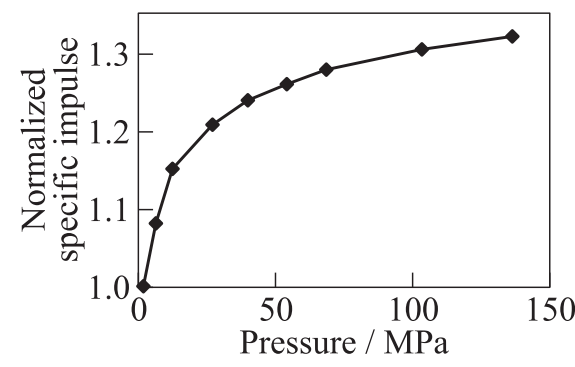

Figure 1 Effect of pressure on calculated propellant theoretical specific impulse
Increasing the operating pressure of the solid rocket motor is one means of increasing the propellant specific impulse without the use of potentially expensive changes in formulation. Increased motor operating pressure is a viable performance option with the development of composite motor case technology. Potential performance increases that may be achieved with an increase in operating pressure are illustrated in the normalized theoretical specific impulse of Fig. 1 for a typical AP/

hydroxy-terminated polybutadiene (HTPB) propellant. The theoretical specific impulse at each operating pressure was divided by that at $6.9 \mathrm{MPa}$ to obtain the normalized values. Optimal expansion ratios were used in the calculations for each pressure. Pressure also has a strong effect on the propellant burning rate.

Typically, burning rates are measured over the expected operating pressure of the propulsion system. The measurement of burning rates at pressures above those of typical rocket motor operating pressures are used to understand the potential for anomalous behavior of the energetic fill in a hazardous event such as fragment impact or cookoff. Solid propellant combustion at pressures above $14 \mathrm{MPa}$ has suffered from the problems of high burning rate pressure exponent as well as increased combustion instability. Until recently, the measurement of propellant burning rates at pressures above $14 \mathrm{MPa}$ was limited while pressures above $40 \mathrm{MPa}$ continue to be rare.

\section{BACKGROUND}

The propellant burning rate, in its simplest form, is the rate of conversion of solid to gas in a direction normal to a planar burning surface. The Saint RobertVieille law is often used to describe the burning rate over limited ranges of pressure:

$$
r=b p^{n}
$$

where $r$ is the linear burning rate; $p$ is the pressure; $n$ is the burning rate pressure exponent; and $b$ is the constant of proportionality. The sensitivity of the burning rate to changes in pressure increases as $n$ approaches unity and can cause rocket motor performance to suffer. Although not a cause of combustion instability, a change in the burning rate pressure exponent may promote instability. Linear theory predicts that acoustic driving should increase as the burning rate exponent 
increases [1]. Small changes in the motor operating pressure at $n=1$ will result in large changes in the burning rate and may lead to a hazardous event such as a motor failure.

Typically, the Saint Robert - Vieille law does not hold over a broad pressure range, and solid rocket propellants will exhibit a "slope break," or change in the burning rate pressure exponent at a characteristic pressure, $p^{*}$, where the burning rate changes from a lower to a higher value. The "slope break" is often observed in AP-based propellants at pressure above $14 \mathrm{MPa}$. The location of $p^{*}$ is a critical ballistic design parameter. Ideally, rocket motor operating pressures should not overlap with a break in the burning rate pressure exponent.

Ammonium perchlorate is a common oxidizer in solid rocket motor formulations and is a monopropellant that will self-deflagrate at pressures above $2 \mathrm{MPa}$. The changes in the burning rate pressure exponent in propellants based on AP are associated with the gas phase reactions controlling the AP monopropellant burning rate. The self-deflagration rates of neat AP are plotted in Fig. 2 for both pressed pellets and single crystals. There is agreement among investigators at pressures less than $13.8 \mathrm{MPa}$. There are considerable differences in the pressure region between 13.8 and $27.6 \mathrm{MPa}$ primarily due to unstable burning in this pressure regime and a critical dependence on the method of data reduction. The burning becomes more stable at pressures above $27.6 \mathrm{MPa}$ with the dominance of gas-phase reactions. The burning rate curve takes on a high positive pressure exponent in the gas phase dominated zone. The high slope region of the neat AP appears to be a limiting factor in achieving high-pressure burning rates with a low burning rate pressure exponent and has been referred to as the "AP barrier," represented by the line in Fig. 2 [2-6]. The change in burning rate

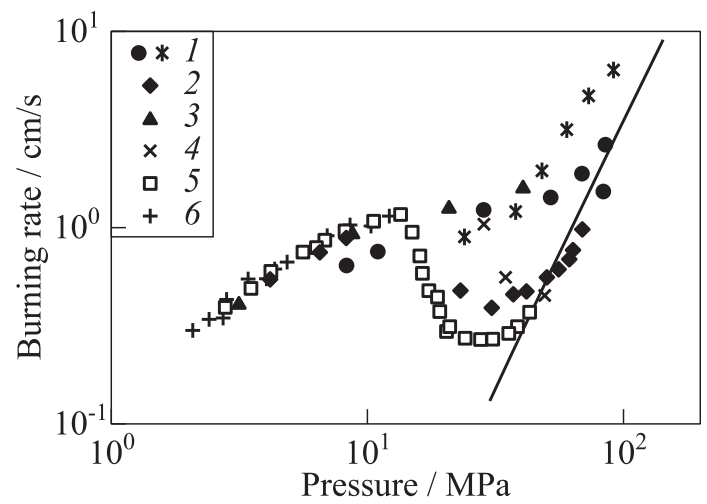

Figure 2 Neat AP burning rate data from various investigators: $1-[2]$; pressed pellets: $2-[3], 3-[4]$, and $4-[2]$; and single crystals: $5-[5]$, and $6-[6]$. Line - AP barrier 
pressure exponent has been observed to occur at pressures to the left (less than) of the "barrier."

\section{TECHNIQUE}

Burning rates were obtained over a range of pressures from 1 atm to about $345 \mathrm{MPa}$. The burning rates illustrated in this paper were generated using a technique that incorporates both low- and high-loading density combustion bombs. The technique involves the use of a combination of cinephotomicroscopy and closed bomb testing.

Combustion bombs have been widely used to assess propellant combustion behavior for many years. Highly loaded closed bomb techniques are heavily used in the gun and explosives communities, with limited use by the solid rocket propellant community. The solid rocket propellant community has used the closed bomb for the evaluation of propellant friability and its propensity for deflagration-to-detonation transition (DDT) [7]. Strand or window burners have had more use in the solid propellant community. There are numerous types and styles of combustion vessels, but they can be divided into two categories based

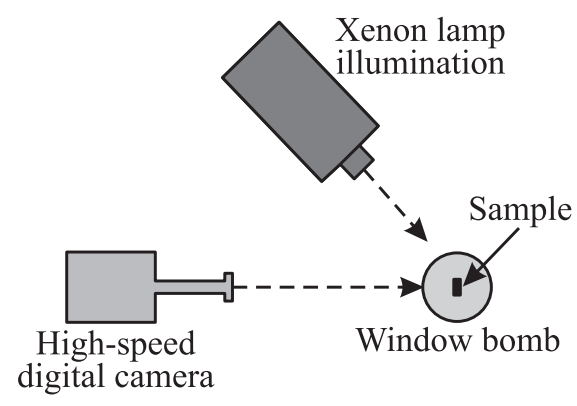

Figure 3 A schematic of the window bomb burning rate apparatus on their loading density, or the weight of the sample divided by the total bomb volume. Low loading density bombs $\left(<0.007 \mathrm{~g} / \mathrm{cm}^{3}\right)$ experience little pressure rise during a test, and high loading density bombs $\left(>0.02 \mathrm{~g} / \mathrm{cm}^{3}\right.$ ) see pressure rises greater than $14 \mathrm{MPa}$ during a test.

A window bomb technique (low loading density) was used to generate burning rate data from ambient pressure to about $55 \mathrm{MPa}$. A schematic of the experimental system is shown in Fig. 3. Since little pressure is generated in these bombs during a test,

they must be pressurized to the specific pressure of interest. The test sample is photographed using a high-speed digital camera at a framing rate of 500 pps and $1 \mathrm{X}$ magnification. The burning rate is determined directly by measuring the sample regression of the spatially and temporally calibrated image. If needed, higher magnification and framing rates can be used to obtain an accurate description of the combustion process. The experimental error in measurement is due primarily to the clarity of the image and the planarity of the burn front progression. Typical burning rate variations at each pressure range between $2 \%$ 
and $5 \%$. The instrumental accuracy of the technique would then be less than or equal to $2 \%$.

With high loading density, closed bomb operates at an increasing pressure due to the mass of propellant gasses added during the burning event. The pressure vs. time history is collected over the event, and the reduction to burning rate relies on the following:

1. The burning surface is known and input as a geometric form function. All surfaces are simultaneously ignited and regress uniformly, and the regression rate depends only on pressure and propellant temperature.

2. Heat losses from the bomb are minimal.

3. The equation of state for the gases is known.

Burning rates at pressures from 34.5 to $345 \mathrm{MPa}$ are generated using a Harwood manufactured powder bomb. The vessel end closure is fitted with the igniter leads and pressure gage. Venting is through the opposite end of the vessel. Inside of the bomb is fitted with a stainless steel liner to protect the inner surface and to change the bomb volume if needed. Ignition is by a MK2 electric squib and a portion of DuPont smokeless powder acting as aide. A schematic of the closed bomb system is shown in Fig. 4. Pressure-time data are acquired using a Kistler model $607 \mathrm{C} 4$ pressure transducer. The amplified signal is digitized and recorded on a

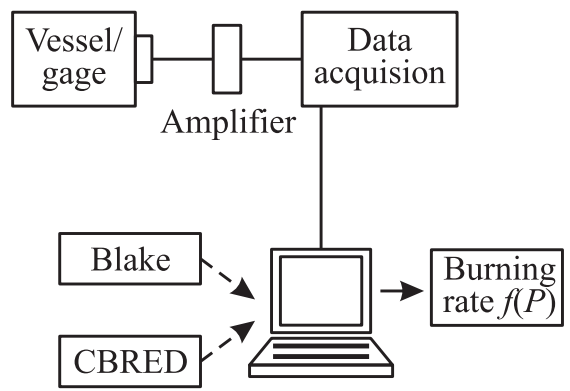

Figure 4 Schematic of the closed bomb system Multipro data acquisition system.

The recorded pressure-time history is first subjected to smoothing and differentiation prior to its conversion to a mass regression rate, $\mathrm{m}$. The BLAKE thermochemical code [8] is used to obtain the thermochemical parameters of impetus, covolume, temperature, and specific heat as a function of pressure for the propellants. The program was developed for Carbon, Hydrogen, Oxygen, Nitrogen $(\mathrm{CHON})$ systems and is limited with respect to materials containing $\mathrm{AP}$ and aluminum. An expanded version of Tiger [9] has been used to improve the thermochemical data.

Closed bomb reduction transforms the measured pressure time history into a mass regression rate through the application of an equation of state. The Closed Bomb Reduction (CBRED) code is employed to reduce the pressuretime data [10]. The CBRED uses a Noble-Able covolume equation of state: 


$$
P\left(V_{s}-n w_{e}\right)=w_{p} F
$$

where $P=$ system pressure $V_{S}=$ system volume; $n=$ covolume; $w_{e}=$ weight of explosive burned; and $F$ =impetus, $f$ (temperature, molecular weight).

One of the options to the CBRED analysis is the ability to introduce the equation of state parameters as a function of pressure. This option is particularly important at the lower pressure regions of the burning rate curve where the thermochemistry is most sensitive to pressure.

The equation is employed in the differentiated form, along with a differentiated energy balance (accounting for the heat losses) to derive the mass rate of gasification as a function of time. The mass regression rate $(\dot{m})$ is the product of the burning surface area $\left(A_{b}\right)$, the sample density $(\rho)$, and the linear burning rate $(r)$ :

$$
\dot{m}=\rho r A_{b}
$$

Undamaged samples of a known geometry are used to determine the burning rate as a function of pressure. The measured pressure-time history from a closed bomb firing is converted to a mass regression rate based on thermochemistry as determined from the thermochemical equilibrium code (BLAKE in this study). The BLAKE code was originally written for gun propellants that do not include AP in their formulations; however, the version used for this study includes gaseous HCL in its product library, and it should be sufficient for the analysis at high pressure. Condensed phase products, such as aluminum, are a shortfall in this code.

An accurate description of the surface area $\left(A_{b}\right)$ described by form function, the simultaneous ignition of all surfaces, and the uniform regression of the surfaces are some of the normal assumptions made in the reduction of closed bomb data to burning rate. No surface inhibitors were used in the closed bomb samples in this study, allowing for ignition on all sides. A change in the surface area due to deconsolidation can have an adverse effect on the results. Large single sample pieces are more difficult to ignite than smaller uniform samples. Bulk propellant samples were cut into 1-centimeter cubes, when practical, to improve ignition.

The burning rate measurement technique is illustrated in Fig. 5 for a typical solid rocket propellant. The closed bomb burning rates obtained at two loading densities are plotted in Fig. $5 a$. The low-pressure measurements are plotted from 0.09 to $55 \mathrm{MPa}$ in Fig. $5 b$. The combined data can be seen in Fig. $5 c$. The combined data can then be fitted to generate a composite burning rate curve. Closed bomb burning rates are typically not reliable at pressures where transient combustion occurs, making the direct photographic measurements more reliable in this regime. 


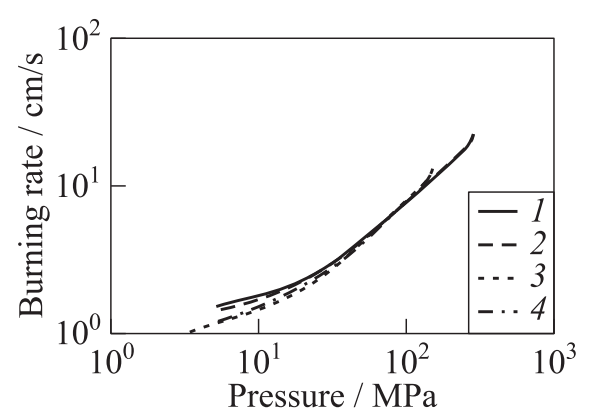

(a)

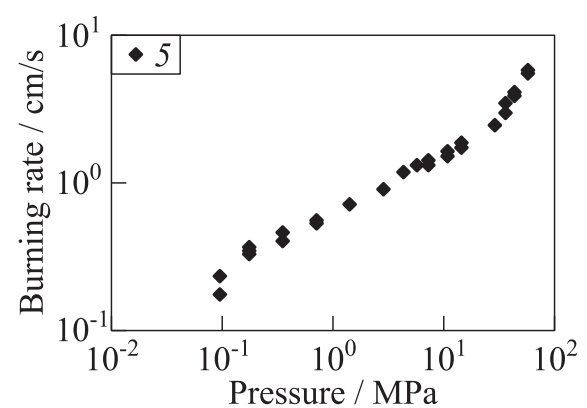

(b)

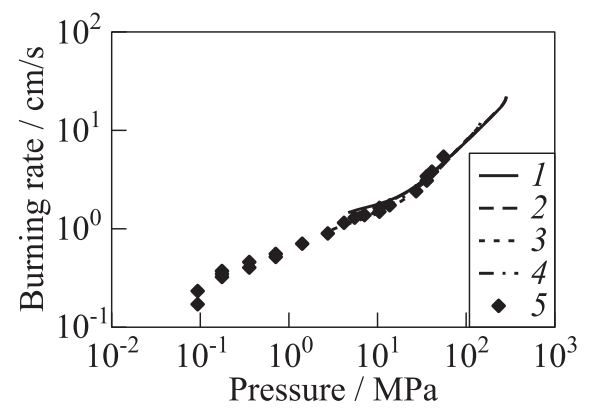

(c)

Figure 5 Burning rate vs. pressure as determined by $(a)$ closed bomb, $(b)$ cinephotomicroscopy, and $(c)$ combined data: 1 - high loading density $1 ; 2$ - high loading density $2 ; 3$ - low loading density $1 ; 4$ - low loading density 2 ; and 5 - window bomb

\section{SAMPLES}

A series of propellants was selected to illustrate the technique used for the evaluation of burning rate over a broad pressure range. The propellants were not specifically formulated for this study, which would be optimum. The increased interest in investigating the impact of high-pressure burning with respect to hazards such as cookoff and fragment impact has resulted in a need for measurement of burning rates at pressures above their operational region. The high-pressure burning rate data are used in the analysis of propellant friability and thermal damage studies of propellants and as input into the modeling and simulation of both cookoff and fragment impact scenarios.

A series of nine metalized AP-based propellants were examined in this study. All of the propellants were metalized and cured with isophorone diisocyanate (IPDI). Three of the propellants listed in Table 1 were formulated with dioctyl 
Table 1 Dioctyl sebacate plasticized AP/HTPB propellants

\begin{tabular}{lccr}
\hline \multirow{2}{*}{ Ingredients } & \multicolumn{3}{c}{ Propellant, \%(wt.) } \\
\cline { 2 - 4 } & $\mathrm{A}$ & $\mathrm{B}$ & $\mathrm{C}$ \\
\hline $\mathrm{R} 45 / \mathrm{IPDI} / \mathrm{DOS}$ & 10.0 & 10.0 & 10.0 \\
$\mathrm{Al}(20 \mu \mathrm{m})$ & 50.0 & 20.0 & 20.0 \\
$\mathrm{AP}(200 \mu$ & & 48.8 \\
$\mathrm{AP}(400 \mu \mathrm{m})$ & & 50.0 & \\
$\mathrm{AP}(20 \mu \mathrm{m})$ & 20.0 & 20.0 & 20.0 \\
$\mathrm{Fe}_{2} \mathrm{O}_{3}$ & & & 1.2 \\
\hline
\end{tabular}

Table 2 Dioctyl adipate plasticized AP/HTPB propellants

\begin{tabular}{lrrr}
\hline \multirow{2}{*}{ Ingredients } & \multicolumn{3}{c}{ Propellant, \%(wt.) } \\
\cline { 2 - 4 } & $\mathrm{W}$ & \multicolumn{1}{c}{$\mathrm{X}$} & $\mathrm{Y}$ \\
\hline $\mathrm{R} 45 / \mathrm{IPDI} / \mathrm{DOA}$ & 12.0 & 12.0 & 12.0 \\
$\mathrm{Al}$ & 18.0 & 18.0 & 19.0 \\
$\mathrm{AP}(200 \mu \mathrm{m})$ & 20.0 & 52.3 & 48.3 \\
$\mathrm{AP}(400 \mu \mathrm{m})$ & 39.0 & & \\
$\mathrm{AP}(20 \mu \mathrm{m})$ & 10.0 & 17.4 & 20.7 \\
$\mathrm{Fe}_{2} \mathrm{O}_{3}$ & 1.0 & 0.3 & \\
\hline
\end{tabular}

Table 3 Nitro-plasticized AP propellants

\begin{tabular}{lccc}
\hline \multirow{2}{*}{ Ingredients } & \multicolumn{3}{c}{ Propellant, \%(wt.) } \\
\cline { 2 - 4 } & CL1 & CL2 & CL3 \\
\hline CAPA/plasticizers & & & 15.6 \\
CAPA/plasticizers/DOA & 16.0 & 14.6 & \\
AP $(200 \mu \mathrm{m})$ & 43.5 & 44.0 & 43.4 \\
AP $(20 \mu \mathrm{m})$ & 21.5 & 21.9 & 21.0 \\
Al & 19.0 & 19.5 & 20.0 \\
\hline
\end{tabular}

sebacate (DOS) as the plasticizer. The series will be used to examine particle size and catalyst effects.

Dioctyl adipate (DOA) replaced the DOS plasticizer in the propellants listed in Table 2, and the solids loading was reduced by $2 \%$ primarily in the aluminum fraction. Two of the propellants are iron oxide catalyzed with propellant, Propellant $\mathrm{W}$, containing two times the coarse to fine ratio of that of Propellant $\mathrm{X}$ but three times the level of catalyst.

The HTPB binder system was replaced by a polycaprolactone system in the propellants of Table 3. The solids loading decreased to 84 and $85.4 \%$ (wt.), respectively. These dimeryl diisocyanate (DDI) cured propellants were formulated with mixed plasticizers, but all of the formulations contained the energetic nitroplasticizer, trimethylolethane trinitrate (TMETN).

\section{RESULTS}

The DOS-plasticized propellants are plotted in Fig. 6. The effect of AP oxidizer particle size on propellant burning rate is illustrated for PropA, with 200-micron $\mathrm{AP}$ in the coarse fraction, and for Propellant B, with 400-micron AP in the 


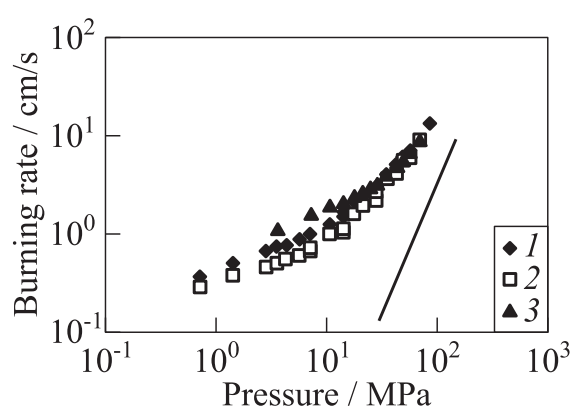

Figure 6 The DOS-plasticized propellant burning rate vs. pressure data for Propellants A (1), B (2), and C (3). Line - AP barrier

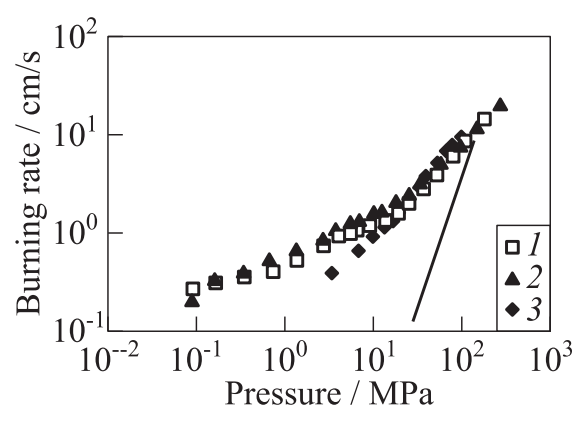

Figure 7 The DOA-plasticized propellant burning rate vs. pressure data for Propellants W (1), X (2), and Y (3). Line - AP barrier

coarse fraction along with the AP burning rate "barrier" discussed earlier. The characteristic pressure, $P^{*}$, was shifted from about $10 \mathrm{MPa}$ in Propellant A to $8 \mathrm{MPa}$ in Propellant $\mathrm{B}$ and to $20 \mathrm{MPa}$ in Propellant C. The burning rate of Propellant A at $14 \mathrm{MPa}$ is about $30 \%$ higher than of Propellant B with the coarser AP at the same pressure. The burning rate of the catalyzed Propellant $\mathrm{C}$ is about $30 \%$ higher than of Propellant A at $14 \mathrm{MPa}$. The particle size and catalytic effects appear to be lost at pressures above $P^{*}$.

Burning rate vs. pressure data are plotted for the DOA-plasticized propellants in Fig. 7. The $P^{*}$ occurs at 18,21 , and $22 \mathrm{MPa}$ for Propellants W, X, and $\mathrm{Y}$, respectively. The $P^{*}$ did not increase with burning rate in this series of propellants. This effect has also been observed in other DOA-plasticized propellants [11]. The catalytic effect on the burning rate is again lost above $P^{*}$.

The burning rate of Propellant $\mathrm{X}$ at $14 \mathrm{MPa}$ is about $53 \%$ higher than of propellant without catalyst (Propellant Y) but with a higher AP coarse-to-fine $(\mathrm{C} / \mathrm{F})$ ratio of about $3: 1$. The burning rate of Propellant $\mathrm{W}$ with a $\mathrm{C} / \mathrm{F}$ ratio of $6: 1$ at $14 \mathrm{MPA}$ is about $18 \%$ higher than of Propellant $\mathrm{Y}$ without catalyst and $23 \%$ lower than that of Propellant X. These data suggest that for these formulations, the amount of fine AP has a stronger effect on the burning rate than the level of catalyst. Examination of the high-pressure burning of the catalyzed propellants was the intent of examining Propellants $\mathrm{W}$ and $\mathrm{X}$; however, it is interesting to note that at the low pressure level, it appears that Propellant X, with the lower level of catalyst, has a higher pressure deflagration limit than the lower burning Propellant W, with the higher catalytic level. Further study is needed to verify this observation.

The effect of replacing DOS plasticizer with DOA can be seen in the comparison of Propellant $\mathrm{Y}$ to Propellant A in Fig. 8. The overall burning rate was 


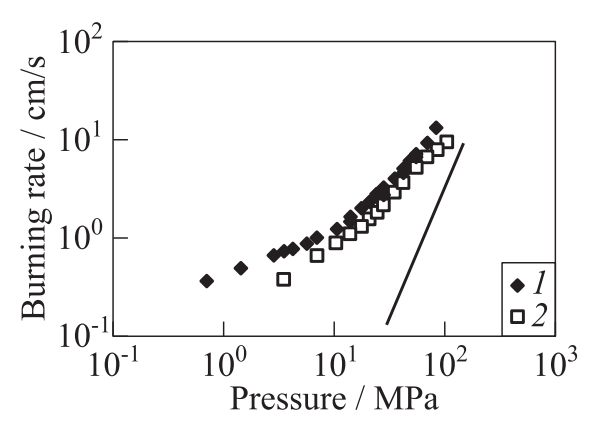

Figure 8 Effect of plasticizer on AP propellant burning rates: 1 - DOS; and 2 - DOA. Line - AP barrier

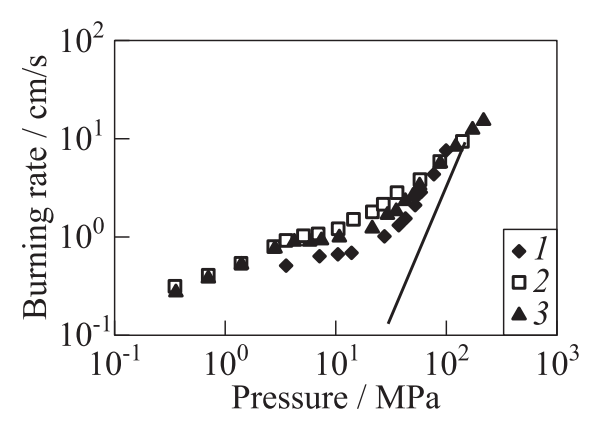

Figure 9 A comparison of nitroplasticized AP-based propellants: 1 CL1; $2-$ CL2; and 3-CL3. Line AP barrier

Table 4 The AP propellant burning rate exponents and characteristic pressure data

\begin{tabular}{cccc}
\hline Propellant & $P^{*}, \mathrm{MPa}$ & $n$ (below $P^{*}$ ) & $n$ (above $P^{*}$ ) \\
\hline A & 10 & 0.36 & 1.09 \\
$\mathrm{~B}$ & 8 & 0.32 & 1.11 \\
$\mathrm{C}$ & 20 & 0.43 & 1.11 \\
$\mathrm{~W}$ & 18 & 0.39 & 0.98 \\
$\mathrm{X}$ & 21 & 0.27 & 0.93 \\
Y & 22 & 0.81 & 1.16 \\
CL1 & 24 & 0.03 & 1.70 \\
CL2 & 15 & 0.23 & 0.80 \\
CL3 & 21 & 0.09 & 1.17 \\
\hline
\end{tabular}

reduced in the DOA-plasticized propellant with $P^{*}$ occurring at about $22 \mathrm{MPa}$ as compared to $10 \mathrm{MPa}$ for Propellant A.

Burning rates of the nitro-plasticized propellants are plotted in Fig. 9. The ratio of energetic plasticizer to DOA was reversed from $3: 1$ to $1: 3$ in the comparison of the CL1 and CL2 propellant burning rates. The CL1 characteristic pressure occurs at $24 \mathrm{MPa}$ preceded by a low burning rate pressure exponent of 0.03 and followed by a very high exponent of 1.7 - the highest observed in this study. $P^{*}$ occurs at 15 and $21 \mathrm{MPa}$ in CL2 and CL3, respectively. The burning rate of CL1 at $14 \mathrm{MPa}$ is about $53 \%$ lower than of CL2. The burning rate of CL1 is about $50 \%$ lower than of CL3.

Table 4 summarizes the burning rate pressure exponent data for the nine AP-based propellants. It also lists the $P^{*}$ data. 
It was concluded in early research [12] that $P^{*}$ would increase as the burning rate increased in AP-based propellants regardless of binder type. This was not found to always be the case in this study, as is illustrated in Fig. 10 for the extremes of the HTPB-based formulation Propellant B with a $P^{*}$ of $8 \mathrm{MPa}$ and of CL1 with a $P^{*}$ of $24 \mathrm{MPa}$ where the CL1 propellant has a lower burning rate than the propellant but a higher $P^{*}$.

The DOS-plasticized propellants were the only formulations investigated in this study that

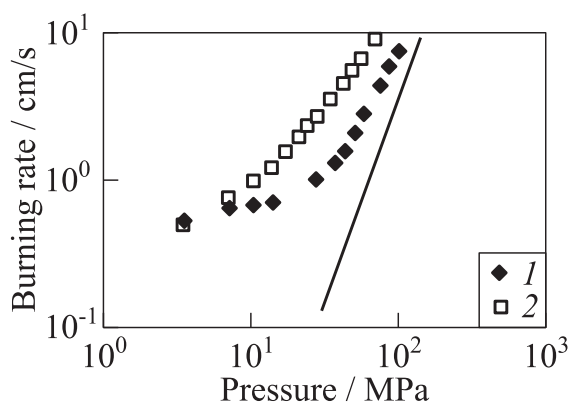

Figure 10 The AP propellant burning rates: 1 - CL1; and 2 - Propellant B. Line - AP barrier demonstrated an increasing $P^{*}$ with increasing burning rate.

\section{CONCLUDING REMARKS}

Two combustion bomb techniques have been combined to obtain burning rate data over a large range of pressures. The lower loading density window bomb technique is used to obtain the data at pressures where the closed bomb data are considered inaccurate due to the mismatch in thermochemistry. The lowpressure closed bomb data can be improved by varying the thermochemistry as a function of pressure in the data reduction. Closed bomb burning rates are indirect measurements, and care must be taken to ensure that the sample is uniformly ignited and burns uniformly.

All of the AP-based propellants tested exhibited a change in burning rate exponent at pressures less than or equal to the AP monopropellant burning rate. It appears that at pressures above $P^{*}, \mathrm{AP}$ is controlling the combustion process. The relationship between burning rate and characteristic pressure, $P^{*}$, was not consistent in this study as an increase in burning rate did always result in a higher $P^{*}$. Burning rates below $P^{*}$ increased with the addition of the iron oxide catalyst and appeared to have little or no effect on the burning rate above $P^{*}$. The amount of catalyst may have an effect on the pressure deflagration limit, but further studies are needed.

The burning rates and characteristic pressure of propellants formulated with a nitroplasticizer were modified with the changes in the ratio of energetic plasticizer to inert plasticizer. The addition of higher amounts of the plasticizer resulted in an increase in burning rate and a decrease in the characteristic pressure as was observed in CL1 and CL2. 
The results of this study would indicate that the pressure limits of AP-based propellants are about $20 \mathrm{MPa}$. This is a limiting factor for the possible increase in performance with increased motor operating pressures. The relationship of pressure and burning rate pressure exponent in the non-AP containing minimum signature propellants is an area for potential future investigation.

\section{REFERENCES}

1. Raun, R. L., A. G. Butcher, and M. W. Beckstead. 1991. Slope break and high pressure combustion instability. 28th JANNAF Combustion Subcommittee Meeting Proceedings. Chemical Propulsion Information Agency (CPIA) Publication 573. Vol. II. Columbia, Maryland.

2. Glaskova, A.P. 1963. Effect of pressure on the combustion rate of ammonium perchlorate. Russ. J. Appl. Phys. 5:193-202.

3. Bobolev, V.K., A.P. Glazkova, A. A. Zenin, and O. I. Leypunskii. 1964. A study of the temperature distribution in the combustion of ammonium perchlorate. Russ. J. Appl. Phys. 3:153-58.

4. Friedman, R., R. G. Nugent, K. E. Rumbel, and A. C. Scurlock. 1955. Deflagration of AP. 5th Symposium (International) on Combustion Proceedings. New York: Reinhold Publ. Co. 612-18.

5. Boggs, T.L. 1970. Deflagration rate, surface structure, and subsurface profile of self-deflagrating single crystals of ammonium perchlorate. AIAA J. 8(5):867-73.

6. Hightower, J.D., and E. W. Price. 1967. Combustion of ammonium perchlorate. 11th Symposium (International) on Combustion Proceedings. The Combustion Institute. $463-72$.

7. Atwood, A. I., K. P. Ford, D. T. Bui, P. O. Curran, and T. M. Lyle. 2007. Assessment of mechanically induced damage in solid energetic materials. 7 th Symposium (International) on Special Topics in Chemical Propulsion (7-ISICP) Advancements in Energetic Materials and Chemical Propulsion. Kyoto, Japan.

8. Freedman, E. 1998. BLAKE - a thermodynamics code based on TIGER: User's guide and manual. Tech. Report APBRL-TR-02411.

9. Hobbs, M. L., and M. R. Baer. 1992. Nonideal thermoequilibrium calculations using a large product species data base. Sandia National Laboratories (SAND98-0482. UC-741). Albuquerque, New Mexico.

10. Price, C. F., and A. Juhasz. 1977. A versatile user-oriented closed bomb data reduction program (CBRED). Maryland: Army Ballistic Research Laboratory, Aberdeen Proving Ground (BRL R20108).

11. Atwood, A.I., P. O. Curran, C.F. Price, T.L. Boggs, and D. Booth. 1999. High pressure burning rate studies of ammonium perchlorate (AP) based propellants. The Applied Vehicle Technology Panel, AGARD Spring Meeting on Aging Systems: Small Rocket Motor and Gas Generators. Corfu, Greece.

12. Martin, J. D., and C. B. Henderson. 1970. Theory of pressure exponent break in ammonium perchlorate propellants. 26th JANNAF Propulsion Meeting Proceedings. CPIA Publication 196. Columbia, Maryland. 889-93. 